\title{
Does gene horizontal transfer occur in lactic acid bacteria co-cultures?
}

\author{
Gérard Guédon*, Florence Bourgoin, Bernard Decaris
}

\begin{abstract}
Laboratoire de Génétique et Microbiologie, U.A. Inra 952, Université Henri-Poincaré-Nancy I, Faculté des Sciences, B.P. 239, 54506 Vandouvre-lès-Nancy, France
\end{abstract}

\begin{abstract}
Four types of insertion sequences, IS1191, IS981, ISS1 and IS1194, were identified in Streptococcus thermophilus CNRZ368. The ISSI elements can be divided into three subgroups, $\alpha, \beta$ and $\gamma$ sharing 75-85\% nucleotide sequence identity. Mosaic elements resulting from recombination between ISSI belonging to different subgroups were also identified. The IS1191, IS981, $\alpha$ and $\beta$ ISS1 nucleotide sequences from S. thermophilus CNRZ368 were found to be almost identical to insertion sequences from Lactococcus lactis, suggesting that horizontal transfers have recently occurred between these distantly related lactic acid bacteria. IS distribution indicates that horizontal transfers have probably occurred from $S$, thermophilus to L. lactis and from L. lactis to S. thermophilus during cocultures used for cheese manufacture. Furthermore, IS 1194 distribution also suggests that some strains of S. thermophilus and $L$. lactis have acquired this IS by horizontal transfer(s) from an unidentified bacterium. The three ISSI copies, two of the four IS981 copies and the unique IS1194 copy of S. thermophilus CNRZ368 are clustered in the same $12 \mathrm{~kb}$ chromosomal region which could have been acquired from L. lactis. Furthermore, other sequence comparisons showed that horizontal transfers of IS and other genes like citP encoding citrate permease occurred between various species belonging to five genera of lactic acid bacteria, Lactococcus, S. treptococcus, Lactobacillus, Leuconostoc and Enterococcus. (C) Inra/Elsevier, Paris.
\end{abstract}

horizontal transfer / Streptococcus thermophilus / Lactococcus lactis / lactic acid bacteria / insertion sequence

Résumé - Des transferts horizontaux d'information génétique se produisent-ils lors des cocultures de bactéries lactiques ? Quatre types différents de séquences d'insertion, IS1191, IS981, ISS1 et IS1194 ont été caractérisés chez S. thermophilus CNRZ368. Les éléments ISS1 peuvent être répartis en trois sous-groupes, $\alpha, \beta$ et $\gamma$, dont les séquences divergent de 15 à $25 \%$ et des éléments mosaïques résultant de la recombinaison d'ISS1 de sous-groupes différents. Les séquences nucléotidiques de types IS1191, IS981, ISS1 $\alpha$ et $\beta$ de $S$. thermophilus CNRZ368 sont presque identiques à celles des éléments homologues de $L$. lactis, suggérant que des transferts horizontaux se sont produits récemment entre ces deux espèces bactériennes. La distribution de ces éléments suggère que des transferts horizontaux se seraient produits dans les deux sens lors des cocultures de ces deux espèces utilisées dans les fabrications fromagères. De plus, IS1194 aurait

* Correspondence and reprints 
également été acquise chez les deux espèces par des transferts horizontaux à partir d'une espèce bactérienne non identifiée. Les trois copies d'ISS1, deux des quatre copies d'IS981 et l'unique copie d'IS1194 de $S$. thermophilus CNRZ368 sont regroupées dans un fragment chromosomique de $12 \mathrm{~kb}$ qui pourrait avoir été acquis par transfert horizontal à partir de $L$. lactis. Les transferts d'IS et d'autres gènes comme citP codant la citrate perméase concernent des espèces appartenant à cinq genres différents de bactéries lactiques, Lactococcus, Streptococcus, Lactobacillus, Leuconostoc et Enterococcus. (O) Inra/Elsevier, Paris.

transfert horizontal / Streptococcus thermophilus / Lactococcus lactis / bactéries lactiques / séquence d'insertion

\section{INTRODUCTION}

Dissemination of genes encoding resistance to antibiotics or heavy metals and comparison of their nucleotide sequences have provided ample circumstantial evidences for recent horizontal transfer of genetic information between distantly related pathogenic bacteria (i. e. belonging to different genera) in the environment. However, until recently, good evidence of recent intergeneric transfer was only found for resistance genes and for plasmids and transposons which contain these genes.

Cocultures of various lactic acid bacteria are used in manufacture of dairy products. Cocultures of $S$. thermophilus and various other bacteria including $L$. lactis are used as starters in the production of some cheeses. However, until recently, no genetic exchange was observed between these bacterial species.

\section{COMPARISON OF INSERTION SEQUENCES (IS) FROM S. THERMOPHILUS AND OTHER LACTIC ACID BACTERIA}

The study of a chromosomal polymorphic region of $S$. thermophilus CNRZ368 has led to the characterization of an insertion sequence (IS), IS1191, which belongs to the IS256 family [4]. At the same time,
IS905, an IS which is almost identical to IS 1191 (98.3\% identity in nucleotide sequence) was found in L. lactis [3]. Furthermore, one of the IS 1191 copies is inserted in a truncated copy of an unrelated IS, IS981 [4] which belongs to the IS3 family. This type of IS was previously found in L. lactis [6]. Nucleotide sequences of IS 981 from the two species share $99.3 \%$ identity.

Moreover, one of the IS981 copies of S. thermophilus CNRZ368 is interrupted by a third type of IS, ISSISA, which belongs to IS 6 family [1]. The nucleotide sequences of ISSISA and of an ISS1 previously identified in L. lactis, ISS $1 \mathrm{~N}$, share 98.6\% identitity. A phylogenetic tree deduced from the nucleotide sequences of ISSISA and 21 other ISS 1 elements (reviewed in $[1,8]$ ) clearly showed that the IS group is divided into three subgroups which we have named $\alpha, \beta$ and $\gamma$ (figure 1 ). ISS1SA belongs to the $\alpha$ subgroup. Nucleotide sequences of elements belonging to the same subgroup share more than $97 \%$ identity. $\alpha$ and $\beta$ elements share about $85 \%$ identity whereas $\gamma$ sequences share about $75 \%$ identity with $\alpha$ or $\beta$ elements.

Some strains of L. lactis (CNRZ270 and MG1820) contain both $\alpha$ and $\beta$ elements. Furthermore, the nucleotide sequences of ISSISA and of another ISSI copy from $S$. thermophilus CNRZ368, ISS1SC, share only $89 \%$ identity. A detai- 


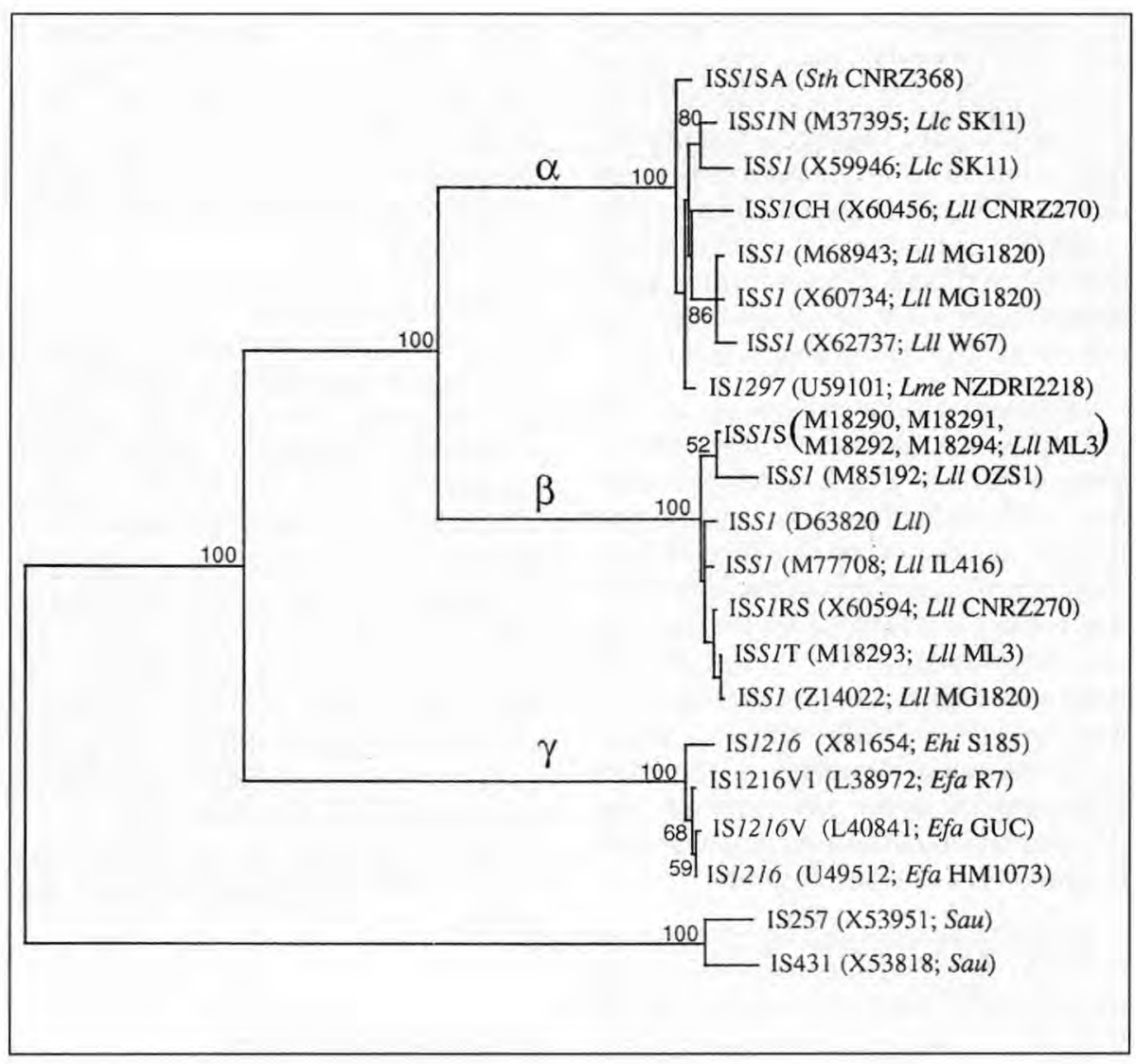

Figure 1. Dendrogram of the ISSI group. The dendrogram was produced by unordered character state parsimony using PAUP program and Heuristic algorithm to find the shortest tree. Nucleotide sequences of IS257 and IS431 from Staphylococcus aureus were used as a monophyletic outgroup. The numbers correspond to the percentage of support for individual nodes on the consensus tree based on 300 bootstrapped runs. Only bootstrapped values greater than $50 \%$ are indicated. The length of the bar corresponds to 10 substitutions. The bacterial host species, subspecies and strains from which each IS was isolated are given: Efa, Enterococcus faecium; Ehi, Enterococcus hirae; Llc, Lactococcus lactis subsp. cremoris; Lil, Lactococcus lactis subsp. lactis; Lme, Leuconostoc mesenteroides; Sau, Staphylococcus aureus; Sth, Streptococcus thermophilus.

Figure 1. Dendrogramme du groupe ISS1. Le dendrogramme a été produit par la méthode du maximum de parcimonie en utilisant le programme PAUP (algorithme « Heuristic ») pour trouver l'arbre le plus court. Les séquences nucléotidiques d'IS257 et d'IS431 de Staphylococcus aureus ont été utilisées comme groupe monophélétique extérieur. Les nombres correspondent au pourcentage de 300 répliques de bootstrap soutenant chaque nœud individuel de l'arbre consensus. Seules les valeurs de bootstrap supérieures à $50 \%$ sont indiquées. La longueur du trait isolé correspond à 10 substitutions. Les espèces, sous-espèces et souches bactériennes hôtes d'où ont été isolées chacune des IS sont indiquées : Efa, Enterococcus faecium; Ehi, Enterococcus hirae; Llc, Lactococcus lactis subsp. cremoris ; Lll, Lactococcus lactis subsp. lactis ; Lme, Leuconostoc mesenteroides; Sau, Staphylococcus aureus ; Sth, Streptococcus thermophilus. 
led comparison of the ISS ISC sequence with those of all the other ISSI elements showed that ISS1SC is a mosaic of two $\alpha$ and two $\beta$ regions suggesting that this element results from recombinations between $\alpha$ and $\beta$ ISS 1 elements [1]. The $\beta$ regions of ISSISC and the corresponding regions of ISS1S, a $\beta$ ISS1 element from L. lactis subsp. lactis ML3, are almost identical ( $98.7 \%$ nucleotide sequence identity).

However, the sequences of the $16 \mathrm{~S}$ and 23S rRNA of $L$. lactis and S. thermophilus share only $89.1-89.2 \%$ identity. According to [5], such divergence suggests that the last ancestor of the two species lived about $6 \times 10^{8}$ years ago. All other nucleotide sequences available for the two species (5S rRNA, tRNA ${ }^{\text {asn }}$, recA and the gene encoding lactate deshydrogenase) have only $71.6-85.1 \%$ identities. Therefore, the quasi-identities of ISs from L. lactis and $S$. thermophilus strongly suggest that horizontal transfers have recently occurred between these species.

Sequence analysis also showed that two iso-ISS 1 elements from L. lactis are mosaics of $\alpha$ and $\beta$ regions [1]. ISSIW from L. lactis $\mathrm{Wg} 2$ is a mosaic of a $\gamma$ region and region sharing only $76-81 \%$ identity with $\alpha, \beta$ and $\gamma$ elements. In the same way, a truncated ISS1 element from L. lactis UC653 (GenBank $\mathrm{n}^{\circ} \mathrm{U60336)}$ is a mosaic of a region sharing $84-88 \%$ identity with $\alpha$ and $\beta$ elements (about 40 bp left sequence), an $\alpha$ region (about $90 \mathrm{bp}$ ), and a $\gamma$ region (about 260 bp right region). Furthemore, a 76 bp region of an iso-ISSI element from Enterococcus hirae S185 (GenBank no X81654) shares only $91 \%$ identity with the corresponding sequence of $\gamma$ ISS1 elements whereas the remaining sequences share $99.2-100 \%$ identity.

$\alpha$ ISSI sequences were found in $S$. thermophilus, L. lactis and Leuconostoc mesenteroides (figure I). In the same way, complete, truncated or partially sequenced $\gamma$ elements sharing more than $99 \%$ identity were found in $E$. hirae, $E$. fae- cium (figure 1), E. faecalis (GenBank $\left.\mathrm{n}^{\circ} \mathrm{U} 17153\right), L$. lactis (GenBank $\mathrm{n}^{\circ}$ U60336) and Lactobacillus sake (GenBank n ${ }^{\circ}$ Z54312). The $16 \mathrm{~S}$ rRNAs of Enterococci, Lactococci, Lb. sake and Lc. mesenteroides share less than $85 \%$ nucleotide identity.

The polymorphism and quasi-identities of ISS 1 from various hosts suggest a three-step evolution. In a first step, the ISSI subgroups have probably appeared by separate evolution of initially identical IS $S I$ elements in different bacteria which did not exchange genes in their natural environment. In a second step, numerous horizontal transfers have occurred between species belonging to five different genera of lactic acid bacteria probably during dairy cocultures. Presence of ISS1 belonging to different subgroups in the same strain probably resulted from this second step. In a third step, mosaic elements appeared by recombinations between ISS 1 belonging to different subgroups.

\section{IS DISTRIBUTION}

IS 1191 related elements were detected by hybridization in all the $28 \mathrm{~S}$. thermophilus strains tested but only in 5 out of the 15 strains of $L$. lactis tested [3, 4] suggesting that IS 1191 was transferred from $S$. thermophilus to L. lactis.

On the contrary, one to four IS 981 copies were found by hybridization in only 15 out of 28 strains of $S$. thermophilus tested whereas all the 30 strains of $L$. lactis tested were found to contain IS981 related elements $[4,6]$. One to three $\alpha$ and/or $\beta$ ISS1 elements are present in 19 out of the 24 strains of $S$. thermophilus tested whereas $\alpha$ and/or $\beta$ ISS1 elements were found, generally in more than 10 copies, in almost all strains of $L$. lactis tested [1]. Therefore, these distributions suggest that 
IS981, $\alpha$ and $\beta$ ISS1 elements were transferred from $L$. lactis to $S$. thermophilus.

S. thermophilus is used as starter in the manufacture of yoghurt and various types of cheeses whereas $L$. lactis is used as starter in the manufacture of most types of cheeses but never in that of yoghurt. Nine of the $10 \mathrm{~S}$. thermophilus strains tested which do not possess IS 981 were isolated from yoghurt whilst 12 of the 13 strains tested isolated from cheeses possess IS981. Thus, this correlation suggests that IS 981 was transferred from $L$. lactis to some strains of $S$. thermophilus during cheese manufacture.

Another IS, IS1194, which belongs to IS 5 family was found downstream from ISS1SA. Only one IS 1194 copy was detected by hybridization in 2 out of the 19 S. thermophilus strains tested and in 4 out of the 15 strains of $L$. lactis tested. These results suggest that IS 1194 was acquired in both species by horizontal transfers from an unidentified bacterium.

\section{HORIZONTAL TRANSFERS OF OTHER SEQUENCES}

Sequence analysis showed that a chromosomal $12 \mathrm{~kb}$ region of $S$. thermophilus CNRZ368 contains the two $\alpha$ ISS1 copies (ISS1SA and $\triangle \mathrm{ISSISB}$ ), the $\alpha \beta$ mosaic copy (ISS1SC), two of the four IS981 copies and the unique IS 1194 copy. This region is included in a variable locus, varD. Four probes which are adjacent to the $12 \mathrm{~kb}$ region hybridized only with two out of the 19 strains of $S$. thermophilus tested, CNRZ368 and A054. These strains are very closely related and possess the $12 \mathrm{~kb}$ region [1]. Therefore, a $23 \mathrm{~kb}$ region could result from the integration of a lactococcal DNA fragment into the chromosome of a common ancestor of the two strains.

\section{CONCLUSION}

Thus, sequence comparison and IS distribution strongly suggest that horizontal transfers have occurred from $S$. thermophilus to $L$. lactis and from $L$. lactis to $S$. thermophilus probably during cocultures used in cheese manufacture. Many horizontal transfers of IS and other genes have probably occurred between various species belonging to five lactic acid bacteria genera which are used as starters in dairy industry. Furthermore, it must be noticed that the citP genes from $L$. lactis and Leuconostoc lactis share $99.2 \%$ nucleotide sequence identity [7] suggesting that this gene has been acquired by a horizontal transfer. This plasmidic gene encodes the citrate permease which allows citrate uptake and its metabolisation in diacetyl, an important flavour compound of butters and creams.

However, the mechanism involved in these transfers remains unknown. The most likely mechanism appears to be conjugative transfer. Some conjugative plasmids like $\mathrm{pAM} \beta 1$ and conjugative transposons like Tn916 which have very broad host range transfer were found in pathogenic Streptococci and Enterococci. Furthermore, a conjugative transposon found in various strains of $L$. lactis, $\mathrm{Tn} 5307$, was recently transferred by conjugation from L. lactis to an Enterococcus strain [2]. However horizontal transfers by natural transformation can not be excluded since at least some pathogenic Streptococci like $S$. pneumoniae are naturally transformable. Furthermore, it must be noticed that bacteria lysis and therefore DNA release occur during cheese ripening. Transduction seems to be more unlikely since no phage infecting different species or genera of lactic acid bacteria is known. 


\section{REFERENCES}

[1] Bourgoin F., Guédon G., Pébay M., Roussel Y,, Panis C., Decaris B., Characterization of a mosaic ISS1 element and evidence for the recent horizontal transfer of two different types of ISS1 between Streptococcus thermophilus and Lactococcus lactis, Gene 178 (1996) 15-23.

[2] Broadbent J.R., Sandine W.E., Kondo J.K., Characteristics of Tn5307 exchange and intergeneric transfer of genes associated with nisin production, Appl. Microbiol. Biotechnol. 44 (1995) 139-146.

[3] Dodd H.M., Horn N., Gasson M.J., Characterization of IS905, a new multicopy insertion sequence identified in lactococci, J. Bacteriol. 176 (1994) 3393-3396.

[4] Guédon G., Bourgoin F., Pébay M., Roussel Y., Colmin C., Simonet J.M., Decaris B., Characterization and distribution of two insertion sequences, IS 1191 and iso-IS981, in Streptococcus thermophilus: does intergene- ric transfer of insertion sequences occur in lactic acid bacteria co-cultures?, Mol. Microbiol. 16 (1995) 69-78.

[5] Ochman H., Wilson A.C., Evolution in bacteria: evidence for a universal substitution rate in cellular genomes, J. Mol. Evol. 26 (1987) 74-86.

[6] Polzin K.M., McKay L.L., Identification, DNA sequence and distribution of IS981, a new high-copy-number insertion sequence in Lactococci., Appl. Environ. Microbiol. 57 (1991) 734-743

[7] Vaughan E.E., David S., Harrington A., Daly C., Fitzgerald G.F., De Vos W., Characterization of plasmid-encoded citrate permease (citP) genes from Leuconostoc species reveals high sequence conservation with the Lactococcus lactis citP gene, Appl. Environ. Microbiol. 61 (1995) 3172-3176.

[8] Ward L.J., Brown J.C., Davey G.P., Identification and sequence analysis of IS 1297 , an ISSI-like insertion sequence in a Leuconostoc strain, Gene 174 (1996) 259-263. 